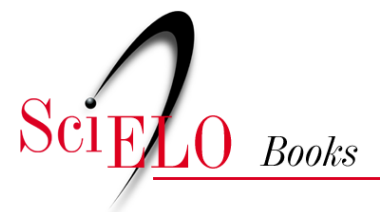

\title{
EDUFU
}

\section{Os mistérios que envolvem a escrita acadêmica}

\author{
Elizabeth Maria da Silva
}

\section{SciELO Books / SciELO Livros / SciELO Libros}

SILVA, E.M. Os mistérios que envolvem a escrita acadêmica. In: AGUSTINI, C., and ERNESTO, B., eds. Incursões na escrita acadêmico-universitária: letramento, discurso, enunciação [online]. Uberlândia: EDUFU, 2017, pp. 141-152. ISBN: 978-65-86084-26-9. https://doi.org/10.7476/9786586084269.0009.

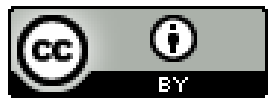

All the contents of this work, except where otherwise noted, is licensed under a Creative Commons Attribution 4.0 International license.

Todo o conteúdo deste trabalho, exceto quando houver ressalva, é publicado sob a licença Creative Commons Atribição 4.0. 


\section{Os mistérios que envolvem a escrita acadêmica}

Elizabeth Maria da Silva

O processo de transição do ensino médio para o ensino superior é marcado, na maioria das vezes, por sentimentos de medo, dúvida, ansiedade e incertezas. É tudo muito novo para os recém-ingressos. No ensino médio, eles estudaram e/ou escreveram, possivelmente, gêneros textuais diversos, que circulam em diferentes esferas sociais, a exemplo de cartas, depoimentos, resenhas jornalísticas, crônicas, artigo de opinião, editorial, entre outros. Todavia, quando chegam ao ensino superior, eles se deparam com gêneros específicos desse ensino: artigos acadêmicos, projetos de pesquisa, ensaios, monografia, etc. Tendo em vista que circulam e são produzidos na esfera acadêmica, é esperado que os estudantes não tenham familiaridade com eles e, consequentemente, não saibam como produzi-los. Surge, assim, uma tensão entre as práticas de escrita que os estudantes já possuem e as que são exigidas pela academia.

Nesse contexto, ao longo dos últimos anos, pesquisas sobre letramentos acadêmicos têm sido desenvolvidas tanto em âmbito internacional (Lea; Street, 1998, 2006; Lillis, 2003; Lillis; Scott, 2003; Zavala, 2009; Street, 2010) quanto, mais recente e paulatinamente, em âmbito nacional (Fischer, 2010, 2011; Marinho, 2010; Fiad 2011, 2013). Pesquisadores têm-se preocupado em apresentar os princípios teórico-metodológicos que fundamentam esse fenômeno, as questões ideológicas e epistemológicas que o subjazem, bem como as aplicações dos letramentos acadêmicos em contexto de ensino de escrita. 
Neste artigo, abordamos, brevemente, essas questões para problematizarmos o processo de solicitação de textos na esfera acadêmica. Para tal, organizamos as ideias em três seções. Na primeira, situamos o contexto histórico no qual o fenômeno dos letramentos acadêmicos surgiu nos Estados Unidos, no Reino Unido e no Brasil, bem como expomos as questões ideológicas e epistemológicas que fundamentam esse fenômeno. Na segunda, discutimos o contexto de ensino da escrita acadêmica, marcado por tensões entre as expectativas dos professores e as interpretações dos estudantes em relação ao que está envolvido nas produções textuais exigidas na universidade. Na terceira e última seção, elencamos algumas alternativas a partir das quais essas tensões podem ser, pelo menos, amenizadas.

\section{Letramentos acadêmicos: contexto histórico, questões ideológicas e epistemológicas}

Para melhor entendermos os pressupostos teórico-metodológicos que ancoram a abordagem dos letramentos acadêmicos, recuperamos o contexto que propiciou o seu surgimento: a expansão da educação superior. Tal expansão ocorreu em vários países, a exemplo dos Estados Unidos, Reino Unido e Brasil, mas em períodos diversos e com desdobramentos distintos.

Nos Estados Unidos, a expansão da educação superior ocorreu no final de 1960 e início de 1970. 0 crescimento da comunidade estudantil universitária desse país - heterogênea e diversificada - trouxe consigo uma necessidade de redirecionamento no ensino de escrita (Bazerman; Prior, 2007 [2004]). Nesse contexto, segundo Russel et al. (2009), surgiu um movimento pedagógico denominado Writing Across the Curriculum WAC, cujo objetivo era incorporar a escrita nas disciplinas ao longo dos currículos universitários, constituindo-se de duas tendências: Writing to Learn - WTL e Writing to Disciplines - WID.

Na segunda tendência do WAC, a WID, enfatiza-se o ensino da escrita em contextos disciplinares específicos, buscando-se desenvolver, tanto nos professores quanto nos alunos, o papel consciente da escrita. Isto, a partir da discussão sobre as necessidades de escrita dos alunos, a maneira pela qual ela funciona em cada uma das disciplinas e o modo como os estudantes podem se envolver ainda mais com ela dentro de cada matéria. Além disso, de acordo com Russel et. al. (2009), há uma preocupação em não trabalhar apenas com estruturas de gêneros, mas, principalmente, com as práticas nas quais eles estão inseridos, de modo 
que o discente possa compreender a funcionalidade que a escrita assume em determinada comunidade disciplinar.

No Reino Unido, a expansão universitária, ocorrida no final de 1980 e início de 1990, também se configurou como parte de uma ação governamental relativa à ampliação de acesso à educação superior, visando à inclusão tanto de estudantes locais quanto internacionais. 0 aumento no número de estudantes nesse nível de ensino, assim como aconteceu nos Estados Unidos, foi acompanhado pela presença de uma diversidade linguística, social e cultural que eles traziam consigo, além de dificuldades em relação à escrita acadêmica. Essas dificuldades eram justificadas pelo discurso oficial e por professores da educação superior a partir do argumento de que os alunos ingressavam na universidade com muitas lacunas no tocante à linguagem escrita, fato que estava gerando uma crise nesse nível de ensino. Logo, segundo Lea e Street $(1998,2006)$ e Lillis e Scott (2003), acreditava-se que, se cursos fossem ministrados com vistas a sanar as lacunas linguístico-textuais, essa crise seria resolvida.

Lea e Street (1998), discordando desse argumento de que a crise na educação superior, no Reino Unido, é devida às deficiências dos alunos, defendem que os problemas deles com a escrita parecem ser mais no nível epistemológico do que linguístico. Defendem ainda que esses problemas são causados, frequentemente, pelas lacunas entre as expectativas dos professores e as interpretações desses estudantes em relação ao que está envolvido nas escritas deles. É nesse contexto que propõem os letramentos acadêmicos como uma perspectiva a partir da qual as escritas dos estudantes poderiam ser entendidas.

Segundo esses autores, há três principais perspectivas ou modelos, que não se excluem e, por vezes, aparecem sobrepostos, a partir dos quais a escrita se configura na educação superior: study skills, academic socialization e academic literacies.

No primeiro modelo, o study skills, o letramento é concebido como um conjunto de habilidades individuais e cognitivas que os estudantes precisam adquirir e, assim, transferi-las para o contexto acadêmico. Desse modo, o desempenho demonstrado pelos alunos na escrita é resultado apenas dessas suas habilidades, sendo, portanto, eles mesmos os responsáveis pelo sucesso ou insucesso que apresentam nas atividades de escrita.

No segundo modelo, o academic socialisation, o letramento é considerado como um conjunto de variáveis que envolve os modos de falar, 
raciocinar, interpretar e usar as práticas de escrita valorizadas nas áreas e disciplinas da universidade. Nesse sentido, cabe ao professor introduzir os alunos na cultura universitária, com o intuito de que eles assimilem essas variáveis. Dessa forma, é papel do professor promover uma socialização acadêmica, contribuindo para a familiarização dos discentes com as práticas letradas acadêmicas.

No terceiro modelo, o academic literacies, o letramento é visto como uma prática social situada, que varia de acordo com as áreas e disciplinas em que é requerido. Focalizam-se, nesse modelo, a identidade, os significados sociais e os conflitos ideológicos subjacentes às práticas de letramento - estas entendidas, conforme Sreet (2012, p.77), como uma "concepção cultural mais ampla de modos particulares de pensar sobre a leitura e a escrita e de realizá-los em contextos culturais".

Essa noção de letramentos acadêmicos foi desenvolvida por pesquisadores ligados ao grupo dos Novos Estudos de Letramento (Street, 1984; Barton, 1984), no qual se defende que o foco de estudo não está tanto na aquisição de competências, como ocorre na abordagem autônoma, mas, sobretudo, nos significados dos letramentos como uma prática social que varia de acordo com o tempo e o espaço (Street, 2003). Sendo assim, consideram-se os letramentos um fenômeno historicamente situado, que assume significados específicos conforme os propósitos das instituições/grupos sociais em que aparece, bem como das relações de poder e de identidade que o subjazem.

De acordo com Lillis e Scott (2003), a perspectiva dos letramentos acadêmicos surge, portanto, como uma tentativa de promover reflexões sobre questões relativas à aprendizagem da escrita do estudante: (1) Qual a natureza da escrita acadêmica em diferentes contextos? (2) 0 que significa para os participantes fazer escrita acadêmica? (3) Como a identidade está ligada às práticas retóricas e comunicativas na academia?

Nesse sentido, uma das principais características desse modelo dos letramentos acadêmicos consiste na mudança de foco, quando se trata de entender a escrita do texto para as práticas. Não é que o texto será desconsiderado nesse modelo, mas entendido a partir das práticas sociais e culturais em torno das quais aparece. Segundo Lillis e Scott (2003), tal mudança de um único ou principal foco no texto ajudou no momento de considerar as várias dimensões da escrita acadêmica dos estudantes que estavam invisíveis ou permaneciam ignoradas: impacto das relações de poder na escrita 
do aluno; centralidade da identidade; construção do conhecimento ideologicamente inscrito, percepções dos estudantes sobre a escrita.

A investigação no campo dos letramentos acadêmicos tem, assim, uma natureza transformativa, pois há um interesse transformativo na construção de significados, um compromisso em buscar as experiências vividas pelas pessoas na tentativa de explorar o que está em jogo para elas, em contextos específicos (Lillis; Scott, 2003). Considerar os contextos específicos, nos quais a escrita aparece, é entender que o letramento acadêmico não é um fenômeno homogêneo, em que apenas as necessidades do estudante são enfatizadas, o que justifica, em geral, o uso do termo "letramento acadêmico", no singular. Pelo contrário, considerar as especificidades dos contextos significa entender os letramentos acadêmicos, no plural, a partir de questões mais amplas que permeiam a escrita acadêmica, a exemplo das práticas institucionais e das questões de poder (Lillis; Scott, 2003). Compartilhamos dessa segunda acepção, embora reconheçamos, junto às autoras citadas (Lillis; Scott, 2003), a fluidez do uso do termo "letramento acadêmico" que é usado tanto na forma singular quanto na plural, para se referir seja a contextos de pesquisa, seja de aplicação, seja a um mesmo contexto, por meio de um contínuo de ênfase. Tal fluidez se justifica pelas diferenças epistemológicas ligadas à posição ideológica dos pesquisadores que o utilizam.

Quanto à expansão do ensino superior do Brasil, diferentemente da dos Estados Unidos e do Reino Unido, é uma ação recente. Em 2007, foi implantado o Programa de Reestruturação das Universidades - Reuni, cuja proposta principal é o aumento do número de vagas de ingresso, especialmente no período noturno, acompanhada da redução das taxas de evasão e da ocupação de vagas ociosas. ${ }^{1}$ Por ser um fenômeno relativamente novo, não faz nem uma década do seu aparecimento, ainda são pouco conhecidos, no Brasil, os efeitos da expansão universitária para as práticas letradas dos estudantes, embora a reclamação dos professores quanto às dificuldades de escrita dos alunos seja bastante recorrente.

Ferreira (2013), com o objetivo de compreender os letramentos acadêmicos de expansão universitária, desenvolveu uma pesquisa em uma universidade pública federal brasileira criada nesse contexto. A autora buscou observar as especificidades das práticas de letramento na instituição selecionada; identificar as concepções de escrita presentes nos

\footnotetext{
${ }^{1}$ Disponível em: <http://reuni.mec.gov.br/>. Acesso em 23 de maio de 2014.
} 
discursos oficiais e as que orientam as práticas vivenciadas na universidade locus da pesquisa; e observar que significados as práticas de escrita adquirem para os diferentes sujeitos. Para tal, a pesquisadora analisou três dimensões: legislação específica que norteia o fazer acadêmico em nível nacional; documentos oficiais que orientam o fazer universitário na instituição pesquisada; e práticas acadêmicas desenvolvidas no curso de Bacharelado em Ciências e Tecnologia, especificamente nas disciplinas Leitura e Produção de Textos e Empreendedorismo. Os resultados obtidos na pesquisa, segundo Ferreira (2013), evidenciaram a heterogeneidade do contexto analisado, apontando para o fato de que as práticas de letramento são constituídas na e pela relação dos estudantes com a universidade.

Ao revisitarmos, rapidamente, o contexto de expansão da educação superior, nos Estados Unidos, Reino Unido e no Brasil, observamos que é apontada uma relação de causa e consequência entre expansão universitária e ingresso de estudantes com lacunas linguísticas e textuais. Todavia, pensando especificamente na realidade brasileira, entendemos ser necessário refletirmos um pouco mais sobre essa associação e ponderarmos algumas afirmações. Será que antes do Programa Reuni a universidade não recebia estudantes com lacunas de natureza diversa? Será que as dificuldades apresentadas pelos estudantes brasileiros dizem respeito apenas a aspectos linguísticos e textuais? Será que as práticas acadêmicas são explicitadas/ensinadas para aqueles que são novatos na instituição universitária? Continuamos pensando sobre esse assunto na próxima seção, na qual problematizamos um pouco o contexto de ensino da escrita acadêmica.

\section{Solicitação da escrita em contexto acadêmico: tensões entre professores e estudantes}

Alguns pesquisadores, que se têm dedicado ao estudo dos letramentos acadêmicos, buscam apresentar não apenas os princípios teórico-metodológicos que subjazem a esse fenômeno, mas também as suas possíveis aplicações em contexto de sala de aula. Uma das estratégias metodológicas utilizadas para tal é a adoção de uma abordagem etnográfica, que envolve a observação das práticas em torno da produção dos textos, bem como as perspectivas dos participantes sobre os textos e as práticas (Lillis; Scott, 2003). 
No âmbito desse segundo foco da abordagem etnográfica, perspectivas dos participantes sobre os textos e as práticas, Lea e Street (1998), Lillis (2003), Street (2010), Zavala (2009), Fischer (2010, 2011) e Fiad (2011, 2013), ao analisarem reflexões feitas por estudantes sobre as suas escritas acadêmicas, observam aspectos semelhantes nas falas desses sujeitos. Há dimensões "escondidas", subjacentes à avaliação da produção de textos acadêmicos, que não se referem apenas à estrutura do texto, mas também ao enquadramento (gênero, audiência, finalidade), à contribuição (para o conhecimento, para a área de pesquisa, para pesquisas futuras), à voz do autor, ao ponto de vista e às marcas linguísticas (Street, 2010). Os professores exigem tal produção sem explicitar, em geral, os critérios que considerarão no momento da correção, supondo, assim, que os alunos já saibam o que é esperado para escrever. Como os alunos não sabem, surge uma relação conflituosa entre as expectativas do professor e as interpretações do estudante, as quais não se restringem apenas à técnica de escrita e às habilidades de gramática, mas a aspectos relacionados com as relações de poder e de identidade que perpassam as interações entre os participantes.

Nesse contexto, é como se os estudantes participassem, na academia, de um "jogo de adivinhação", pois têm que descobrir quais são as expectativas do professor, ao solicitar determinada produção textual. Um dos estudantes britânicos que participaram como sujeito da pesquisa desenvolvida por Lea e Street (1998), quando indagado sobre as suas atividades de escrita acadêmica, afirmou que era consciente de que a escrita para um professor particular era específica, diferenciando-se da escrita para outro docente. Sentia, desse modo, a sensação de que cada professor parecia querer algo diferente, embora solicitasse o mesmo gênero. A pesquisa dos autores evidenciou, assim, que a escrita dos estudantes variava não apenas conforme o curso e a disciplina, mas também de acordo com o professor, de modo que, às vezes, no interior de um mesmo curso, professores individuais tinham opiniões diferentes sobre a escrita.

Esse "jogo de adivinhação" também tem sido foco de interesse da pesquisadora brasileira Raquel Fiad, a qual tem-se preocupado em observar as reflexões que estudantes universitários fazem em relação às suas escritas acadêmicas, mais especificamente, como elas são vistas em confronto com o que é esperado no contexto acadêmico.

Fiad $(2011,2013)$ desconstrói a tese de que os estudantes chegam à universidade sem saber escrever, questionando a visão de escrita que 


\section{Elizabeth Maria da Silva}

subjaz a essa crença - escrita como uma habilidade genérica, absoluta e aplicável a qualquer contexto. Segundo a autora (2003, p.471):

0 mito de que o aluno deve vir pronto para a universidade para ler e escrever deriva da visão de que letramento implicaria fundamentalmente o domínio de um conjunto de competências de leitura e escrita que os alunos têm de adquirir para depois transferi-las para outros contextos. Essa crença, no entanto, ofusca o fato de que os alunos universitários podem ter um bom domínio da língua, mas isso não os leva necessariamente a terem um bom domínio dos gêneros da esfera acadêmica, ou seja, como não existe uma fase de letramento ou um único letramento, são legítimas suas dificuldades para as práticas dos gêneros acadêmicos.

Nessa perspectiva, assim como as pesquisadoras brasileiras Marinho (2010) e Fischer (2010, 2011), Fiad (2011, 2013) reconhece que, ao entrarem na universidade, os estudantes são incumbidos de produzir diferentes gêneros, com os quais não estão familiarizados em suas práticas de escrita em outros contextos (inclusive escolares) e, na maioria das vezes, são mal avaliados por seus professores. Essa má avaliação é fruto da tensão que se instaura entre o que os professores esperam das escritas e o que os alunos de fato escrevem, como também foi constatado por Lea e Street (1998), Lillis (2003) e Zavala (2009).

Nesse contexto, Fiad $(2011,2013)$ defende a necessidade de analisar o que os estudantes têm a dizer sobre o que escrevem. Em seu trabalho publicado em 2011, evidencia o conflito apontado por estudantes do primeiro ano do curso de Letras, de uma universidade estadual brasileira, mostrando como eles escreviam e como eles deveriam escrever os textos acadêmicos - considerando o leitor do texto, o exercício da reescrita e a importância de uma linguagem organizada e clara.

Já no seu trabalho publicado em 2013, a autora apresenta uma proposta de abordagem da reescrita de textos acadêmicos, a partir da articulação entre uma perspectiva etnográfica de análise da escrita e uma concepção dialógica da linguagem. A partir da noção de text history, proposta por Lillis (2008), Fiad (2011, 2013) defende a importância de analisar as interações em torno da reescrita, considerando o texto e as conversas sobre ele. Segundo ela, "ouvir os outros - no caso, sujeitos que estão no processo de inserção no contexto acadêmico - faz parte do processo de enten- 
dimento desse letramento e também de práticas inovadoras no ensino de gêneros acadêmicos" (p.468). Nesse sentido, analisou os comentários de um texto produzido por estudantes universitário $\mathrm{s}$, com vistas a mostrar que, "no processo de escrita, também os diálogos travados entre os estudantes e seus interlocutores podem se constituir em mais uma prática a ser realizada no ensino da escrita acadêmica" (p.477).

Pasquotte-Vieira (2014) também adotou a noção de text history, mas fez isso para investigar a "história de texto" da dissertação de mestrado de uma mestranda do Curso de Pós-Graduação em Agricultura e Ambiente de uma universidade pública brasileira. Para tal, analisou: (a) a versão escrita da dissertação entregue para o exame de qualificação; (b) as notas escritas dos professores da banca sobre essa dissertação; (c) os comentários orais dos professores e da mestranda durante o exame de qualificação; e (d) os fragmentos extraídos de uma entrevista concedida pela mestranda após o exame. Ao triangular esses dados, a autora verificou que o processo de negociação entre os examinadores da dissertação e a pós-graduanda contribuiu para que esta (re)significasse as práticas acadêmicas de escrita, bem como se (re)posicionasse como um sujeito discursivo situado no lugar sócio-histórico da universidade. Assim, Pasquotte-Vieira (2014), sob a ótica de uma perspectiva etnográfica-linguística, defende que a negociação dialógica é fundamental à integração dos sujeitos às práticas letradas acadêmicas, as quais se desenvolvem nas interações discursivas entre os participantes da esfera acadêmica.

As reflexões feitas tanto pelos estudantes estrangeiros quanto pelos brasileiros, participantes das pesquisas referidas, apontam para a natureza complexa da escrita acadêmica. Também evidenciam a necessidade que eles têm de incorporar uma identidade discursiva, diferente da sua identidade biográfica (Ivanic, 1998),com vistas a atender às exigências do âmbito acadêmico e, assim, poderem ser reconhecidos como membros da academia por parte daqueles que têm o poder de fazê-lo: os agentes de letramento.

Assumir uma identidade discursiva que não é a deles, que não reflete a imagem que eles têm de si, é um desafio para os estudantes: "Eu quero dizer muitas coisas neste ensaio, mas eles não querem ouvir", desabafa um dos sujeitos da pesquisa desenvolvida por Lillis (2003, p.203). Paula está satisfeita por ter aprendido formas acadêmicas, mas não se sente ela mesma, quando escreve. Ela escreve o texto com o conteúdo que é esperado institucionalmente, mas desabafa que vive um conflito: "Quero 
falar, me comportar e ser a mesma que antes e pensar da maneira que eles pensam" [familiares] - constatações de Zavala (2009, p.355), quando analisou uma série de entrevistas feitas com a estudante universitária Paula sobre a sua escrita acadêmica.

Nessa perspectiva, ratificamos a produtividade de continuarmos investigando as percepções dos participantes quanto à escrita acadêmica, uma vez que são intensas e recorrentes as tensões que surgem em torno dessa escrita, haja vista a complexidade de sua natureza.

Na próxima e última seção deste artigo, apresentamos algumas sugestões para lidar com os conflitos em torno da escrita acadêmica.

\section{Alternativas para lidar com as tensões que envolvem a escrita acadêmica}

Em síntese, as pesquisas supracitadas evidenciam a necessidade de reconhecermos os letramentos acadêmicos como uma prática discur siva, social e situada e que está perpassada por ideologias, questões identitárias e relações de poder, as quais, na maioria das vezes, estão invisíveis/implícitas. Tais dimensões "escondidas" devem ser explicitadas para aqueles que querem se tornar membros da academia e, desse modo, ser reconhecidos como tais pelos agentes de letramento.

Nesse sentido, para que os conflitos entre as expectativas dos professores e as interpretações dos estudantes sejam pelo menos amenizados, cabe àqueles explicitarem para estes os critérios que norteiam a avaliação dos textos acadêmicos. Para isso, "precisam ficar claros os motivos pelos quais algumas práticas são privilegiadas no domínio acadêmico em detrimento de outras, qual significado determinada prática de letramento tem nesse domínio, o que significa justificar e argumentar de acordo com as convenções escriturais da academia" (Fiad, 2011, p.363).

Costa (2014, p.11) acrescenta que:

Talvez seja oportuno olhar criticamente a concepção de conhecimento que temos defendido, verificar em que medida o conhecimento é construído ou imposto dentro da universidade, explicitar para nós mesmos, primeiramente, as ideologias que subjazem às práticas de letramento acadêmico tal como elas se configuram hoje, pois de tão naturalizadas, elas parecem ter-se convertido em verdades absolutas. Em seguida, explicitá-las para os estudantes e, se necessário, colocá- las em xeque. 
Além disso, faz-se necessário, como sugere Lillis (2003), considerar o potencial dos talkbacks - um espaço para os estudantes refletirem sobre seu texto, dizerem o que gostam e o que não gostam da sua escrita. A utilização desse recurso pode contribuir para a aprendizagem dos estudantes, haja vista o processo de negociação que se estabelecerá entre professores e alunos no tocante aos elementos que estão envolvidos na produção textual.

Por fim, entendemos que o professor que ensina a escrita acadêmica poderia cultivar o equilíbrio entre despertara consciência críticados estudantes quanto às questões ideológicas e de poder que perpassam a produção dos gêneros e contribuir para que eles dominem o componente linguístico-textual desse gênero, a partir da apresentação de atividades de leitura e escrita, bem como do exercício da reescrita dos textos.

\section{Referências}

BARTON, D. Literacy: an introduction to the ecology of written language. Oxford: Backwell, 1984.

BAZERMAN, C; PRIOR, P. A participação em mundos socioletrados emergentes: gêneros, disciplinaridade, interdisciplinaridade. In: HOFFNAGEL, J. C; DIONÍSIO, A. P. (Organizadores).Escrita, gênero e interação social. Tradução e adaptação de HOFFNAGEL, J. C. São Paulo: Cortez, 2007 p.150-197.

COSTA, E. M. Considerações sobre o letramento acadêmico a partir do novo perfil dos graduandos em Letras/Espanhol. In: Colóquio Internacional Cultura Escrita e Letramento,5,2014, Belo Horizonte, p.1-11.

FERREIRA, M. de Lourdes Santos. Letramentos acadêmicos em contexto de expansão do ensino superior no Brasil. Tese (Doutorado em Educação), Belo Horizonte: UFMG, 2013.

FIAD, R. S. A escrita na universidade. Revista da ABRALIN, v. Eletrônico, n. Especial, p.357-369. 2a parte 2011. <http://www.abralin.org/revista/RVE2/14v.pdf>. Acesso em 14 de abr. de 2015.

FIAD, R. S. Reescrita, dialogismo e etnografia. Linguagem em (dis)curso, Tubarão, SC, v. 13, n. 3, p.463-480, set./dez. 2013.

FISCHER, A. Sentidos situados em eventos de letramento na esfera acadêmica. Revista do Centro de Educação, Santa Maria, v.35, n.1, p.215-228, maio/ago.2010. Disponível em: <http://cascavel.ufsm.br/revistas/ojs-2.2.2/index.php/reveducacao/article/view/2072/1248>. Acesso em 28 de maio de 2014.

FISCHER, A. Práticas de letramento acadêmico em um curso de engenharia têxtil: o caso dos relatórios e suas dimensões escondidas. Scripta, v. 15, n.28, p.37-58, $1{ }^{\circ}$ sem. 2011. Disponível em: <http://periodicos.pucminas.br/index.php/scripta/ article/view/4298/4443>. Acesso em 14 de abr. de 2015. 


\section{Elizabeth Maria da Silva}

IVANIC, R. Writing and identity: the discoursal construction of identity in academic writing. Philadelphia: Jonh Benjamins Publishing Company, 1998.

LEA, M. R; STREET, B. V. Student writing in higher education: an academic literacies approach. Studies in Higher Education. v.23, p.157, June 1998.

LEA, M. R; STREET, B. V. The Academic Literacies Model: theory and applications. Theoryinto practice. v.45, n.4, p.368-377, 2006.

LILLIS, T. Student writing as 'academic literacies': drawing on Bakhtin to move from critique to design. Language and Education, v.3, n.17, p.192-207, 2003.

LILLIS, T.; SCOTT, M. Defining academic literacies research: issues of epistemology, ideology and strategy. Journal of Applied Linguistics, v.4, p.5-32, 2003.

MARINHO, M. A escrita nas práticas de letramento acadêmico. Revista Brasileira de Linguística Aplicada, Belo Horizonte: Alab-Poslin, v.10, n.2, p.363-386, 2010.

PASQUOTTE-VIEIRA, E. Letramentos acadêmicos: um estudo de casos sobre o processo de negociação da escrita em um exame de qualificação. In: Colóquio Internacional Cultura Escrita e Letramento, 5, 2014, Belo Horizonte. Anais... Belo Horizonte, 2014. p.1-10.

RUSSELL, D. R.; LEA, M.; PARKER, J.; STREET, B.; DONAHUE, T. Exploring notions of genre in" academi cliteracies" and "Writing Across the Curriculum": approaches across countries and contexts. In: BAZERMAN, Charles; BONINI, Adair; FIGUEIREDO, Débora (Editores).Genre in a changing world. Fort Collins: The WAC Clearinghouse/West Lafayette: Parlor Press, 2009. p.395-423.

STREET, B. Literacy in theory and practice. Cambridge: Cambridge University, 1984.

STREET, B. What's "new" in new literacy studies? Critical approaches to literacy in theory and practice 2003. Current Issues in Comparative Education, v.5, n.2, 2003. Disponível em: < http://www.tc.columbia.edu>. Acesso em 10 de maio de 2014.

STREET, B. Dimensões "escondidas" na escrita de artigos acadêmicos. Tradução de Armando Silveiro e Adriana Fischer. Perspectiva: Revista do Centro de Ciências da Educação - UFSC, Florianópolis, v.8, n.2, jul./dez. 2010. Disponível em:<https://periodicos.ufsc.br/index.php/perspectiva/article/view/2175-795X.2010v28n2p541/18448>. Acesso em 10 de maio de 2014.

ZAVALA, Virgínia. “QQuién está dicendo eso?” Literacidad académica, identidade[y poder en la educación superior. In. KALMAN; STREET (Coord.). Lectura, escritura e Matemáticas. México: Siglo XXI. p.348-363, 2009. 